\title{
Neuro-Behçet's Disease: A Review of Neurological Manifestations and Its Treatment
}

Livia Almeida Dutra and Orlando Graziani Povoas Barsottini

General Neurology Division, Department of Neurology and Neurosurgery, Universidade Federal de São Paulo, São Paulo, Brazil

*Corresponding author: Livia Almeida Dutra, General Neurology Division, Department of Neurology and Neurosurgery, Universidade Federal de São Paulo, São Paulo, Brazil, Tel: +551155764848; E-mail: liviaadutra@hotmail.com

Received date: May 24, 2016; Accepted date: June 24, 2016; Published date: June 28, 2016

Copyright: (C) 2016 Dutra LA, et al. This is an open-access article distributed under the terms of the Creative Commons Attribution License, which permits unrestricted use, distribution, and reproduction in any medium, provided the original author and source are credited.

\begin{abstract}
Behçet's disease (BD) is an inflammatory disorder characterized by recurrent oral and genital ulcers, ocular inflammation, arthritis and skin lesions. Neuro-Behçet's disease (NBD) is found in 5-30\% of patients and is classified into parenchymal and non-parenchymal manifestations. Most common parenchymal NBD manifestation is brainstem meningoencephalitis and patients may also have cranial nerve palsies, myelitis, epilepsy and peripheral neuropathy. Non-parenchymal NBD manifestations are cerebral venous thrombosis and aseptic meningitis. NBD usually develop abruptly and generally clear completely within weeks, however a third of patients evolve with progressive course. Moreover, patients with BD without overt neurological manifestations may present silent neurological involvement, with abnormal findings on neuropsychological, neurophysiological and neuroimaging studies. NBD is an adverse prognostic factor. Herein we review NBD manifestations and its treatment.
\end{abstract}

Keywords: Behçet's disease; Neuro-Behçet's disease; Myelitis; Epilepsy; Peripheral neuropathy; Cerebral venous thrombosis; Vasculitis memory

\section{Introduction}

Behçet's Disease (BD) is a multi-systemic disease characterized by recurrent oral and genital ulcers, ocular inflammation, arthritis and skin lesions [1,2]. It most commonly affects male young patients, during the third decade of life [3-5]. Diagnosis is based on the clinical criteria of the International Study Group (ISG) and serological markers are usually absent [6,7]. Genetic and environmental factors are implicated in the pathogenesis of BD and its prevalence is significantly higher in the ancient Silk Route, which extends from Eastern Asia to Mediterranean countries [3,5]. HLA- B51 is a risk factor for BD and the disease is usually more severe in such patients [8].

Although it was initially thought that Th1 cells were the main cells mediating $\mathrm{BD}$, the important role of Th17 cells in the pathogenesis of $\mathrm{BD}$ has emerged in recent years [9].BD and auto inflammatory syndromes share common clinical characteristics, such as recurrent self-limited clinical manifestations, significant host predisposition and abnormally increased inflammatory response, with a robust innate component $[10,11]$. Genome-wide association studies have identified associations of BD and IL23R, IL10, STAT4, CCR1- CCR3, KLRC4, ERAP1, TNFAIP3, and FUT2 loci $[12,13]$. Deep resequencing of targeted genes identified additional associations with rare variants in MEFV and NOD2 genes, which are involved in monogenic auto inflammatory syndromes $[12,13]$.

Oral ulcers are the initial symptom in the vast majority of the patients and usually predates other clinical manifestations [13].
However, approximately $5-23 \%$ of the cases patients with NBD present neurological manifestation as first symptom [14-17]. The CNS is involved in $5-30 \%$ of patients with BD most frequently in the form of recurrent meningoencephalitis, cerebral venous thrombosis (CVT), cranial nerve palsies, epilepsy, and episodes of diencephalic and brainstem dysfunction that resembles minor strokes [7,18-20] The involvement of CNS is an adverse prognostic factor[14,21]. Type and frequency of neuro-Behçet's disease (NBD) manifestations are associated with ethnicity, and atypical and rare manifestations are more commonly seen in patients of caucasian and Japanese ancestry $[14,16,17]$. We review the clinical manifestations and treatment of NBD.

\section{Clinical NBD Manifestations}

\section{Parenchymal and non-parenchymal NBD}

NBD is classified into parenchymal and non-parenchymal manifestations. Parenchymal NBD is more frequently found and may occur with or without meningeal inflammation [15]. It classically affects the mesodiencephalic region, internal capsule and pons, determining important edema and occasionally small infarcts and petechial bleeding (Figure 1). Clinically patients may develop hemiparesis, impairment of consciousness as well as cranial nerve palsies. Spinal fluid analysis (CSF) may reveal increased cells and protein, and may also be predominantely neutrophilic $[8,22]$. Raised CSF IL-6 levels are usually associated with raised CSF cell count and protein, and these three parameters have been associated with disease activity and outcome over 3 years [22]. 
Citation: Dutra LA, Barsottini OGP (2016) Neuro-Behçet's Disease: A Review of Neurological Manifestations and Its Treatment. J Vasc 2: 112.



Figure 1: Parenchymal NBD. Asterix: Observe the involvement of the meso diencephalic region. Arrows: Involvement of medulla oblongata, pons and internal capsule.

The reversibility of lesions in parenchymal NBD supports the venous inflammatory pathophysiology and many patients evolve with brainstematrophy after inflammation is resolved [23]. Some of them may present a pseudotumoral form of the disease, usually involving the capsule-thalamic region or cortex, with more severe clinical presentation at diagnosis but with good recovery [24] (Figure 2).

Neurological symptoms and signs seen in BD patients are not necessarily due to NBD, and other neurological conditions such as stroke, migraine, neurotoxicity, malignancy and infections should be ruled out [22]. For that reason, the International Consensus Recommendation criteria for NBD diagnosis were established (Tables 1 and 2). Of note, NBD criteria include as probable NBD those patients with typical NBD manifestations that failed to fulfill ISG criteria (patient with recurrent bipolar ulcers and typical neurological manifestation, for example). 
Citation: Dutra LA, Barsottini OGP (2016) Neuro-Behçet's Disease: A Review of Neurological Manifestations and Its Treatment. J Vasc 2: 112. doi:10.4172/2471-9544.100112

Page 3 of 6



Figure 2: Pseudotumoral NBD. A, B: Flair weighted sequence. Observe pseudotumoral lesion with cortical involvement with proeminent vasogenic edema. C, D: T1 weighted sequence showing no contrast enhancement.

\section{Definite NBD (all of the following three criteria):}

1. Satisfy the ISG criteria for BD

2. Neurological syndrome (with objective neurological signs) recognized to be caused by BD and supported by neuroimaging or CSF

3. No better explanation for the neurological findings

Probable NBD (one of the following two criteria in the absence of a better explanation for the neurological findings):

1. Neurological syndrome as in definite NBD, with systemic BD features but not satisfying the ISG criteria

Table 1: International Consensus Recommendation criteria for NBD diagnosis [19]

Atypical parenchymal NBD such as optic neuritis, seizures, peripheral neuropathy, myelitis and demyelinating syndrome are rarely found in Turkish patients. However, in patients of Caucasian origin or mixed ethnicity such manifestations are more frequently found and present additional difficulties to the diagnosis, considering the low threshold for BD diagnosis in those countries [15,17].
Parenchymal syndrome (one or more of the following presentations at first/subsequent attack(s) or progression)

- Brainstem: symptoms and signs of brainstem involvement including ophthalmoparesis, cranial neuropathy, cerebellar or pyramidal dysfunction.

- Multifocal (diffuse): variable combination of brainstem signs and symptoms, cerebral or spinal cord involvement

\section{- Myelopathy}

- Cerebral: symptoms and signs suggestive of cerebral hemispheric involvement including encephalopathy, hemiparesis, hemisensory loss, seizures and dysphasia, and mental changes including cognitive dysfunction and psychosis

-Optic neuropathy

\section{Non-parenchymal syndromes}

Cerebral venous thrombosis

Intracranial hypertension syndrome (pseudotumour cerebri)

Acute meningeal syndrome

Table 2: Recognized neurological syndromes in NBD [19] 
Headache is the most common neurologic symptom in $\mathrm{BD}$ and most likely to migraine or tension-type headache, and neuroimaging is warrant for the same red flags signs and symptoms as in general population $[8,25]$. However headache is common before and during the attack and 10-15\% of headaches reported in BD can be attributed to an ill-defined entity known as "non-structural headache of BD", when criteria for either NBD or a primary headache disorder are not met $[8,26]$. For that reason, all $\mathrm{BD}$ patients with a recurring headache syndrome, regardless of apparent stability of headache character, require routine neurological examinations to identify "silent neurological involvement" predictive of future onset of NBD, and nonlocalizing pyramidal signs are the typical exam findings $[20,25]$.

Epilepsy frequency varies from $4-27 \%$, according to the population $[16,17,20]$. Seizure can be generalized or focal, and occur during an acute neurologic manifestation of the disease, quiescent phase or progressive form of NBD [23,27-29]. Although previous studies showed that seizures are more commonly secondary to medications and other provoking factors, some patients with NBD and epilepsy may present frontal or hippocampal involvement that justify the occurrence of seizures [23]. The occurrence of seizures is associated with a high mortality rate [29].

NBD may also present with a recurrent clinical course of subacute neurological symptoms suggesting demyelinating syndrome. Brain MRI may show small lesions scattered through the white-matter, and some of them may involve the brainstem [30]. This MRI pattern is different from those found in the classical brainstem encephalitis and may resemble Neuromyelitis optica and Multiple Sclerosis. Thus NBD should be considered in the differential diagnosis of those disorders when there are atypical features and associated systemic symptoms are found $[22,31]$.

Optic neuropathy $(\mathrm{ON})$ is rare, could be uni or bilateral and generally occurs in association with other parenchymal manifestations, however there are reports of isolated ON $[8,14,18]$. It could also be recurrent and patients may be left severely disabled.

Myelitis usually occurs in the setting of systemic activity and in the presence of other lesions involving the basal ganglia, brainstem or cortex [22]. It may be extensive or focal and requires vigorous treatment, because it presents worse prognosis when compared to other neurological manifestations [32-34].

Peripheral neuropathy is rare, and patients may present GuillainBarré syndrome, sensorimotor neuropathy, mononeuritis multiplex, and autonomic neuropathy [21-23], with variable response to treatment $[8,14,35,36]$.

Non-parenchymal NBD manifestations are CVT and aseptic meningitis [14]. Contrary do parenchymal NBD that relapses in $30-50 \%$ of cases, non-parenchymal NBD present good prognosis and rarely recur $[14,18,20]$. Aseptic meningitis is rare and in such cases, care should be taken to exclude infection, particularly in patients who are on immunosuppressant agents [8]. There have been few reports describing hypertrophic pachymeningitis in patients with NBD [37].

Middle West and Turkish series present more cases of CVT and rare cases of aseptic meningitis when compared to other populations $[14,16,17]$. A systematic review on CVT in NBD showed that intracranial hypertension syndrome was the most frequent presentation, being superior sagittal and transverse sinus the most commonly involved [38]. It is believed that CVT in NBD is secondary to an inflammatory process for that reason, although anticoagulation is the standard treatment, in some centers patients are also managed with steroids [22,39]. It is advisable to rule out systemic aneurism before anticoagulation is initiated [22].

Systemic inflammatory disorders such as uveo-meningeal syndromes, sarcoidosis, systemic lupus erythematosus, neuro-Sweet syndrome and Sjogren's syndrome are important differentials diagnosis [22]. Autoinflammatory syndromes such as PFAPA that presents periodic fever, aphthous stomatitis, pharyngitis, and cervical adenitis should also be considered because it shares similar clinical manifestations [40].

NBD may present an acute or chronic course. Most patient present an acute course and approximately $30-50 \%$ relapse, depending on the population evaluated $[14,41]$. Moderate or severe neurological disability was found in $45 \% \mathrm{NBD}$ patients at 10 -year follow-up [42]. It was found that patients with HLA-B51 relapse more often [41]. Other adverse prognostic factor in NBD are brainstem or spinal cord presentation, frequent relapses, early disease progression, residual neurological impairments in remission and high CSF pleiocytosis $[8,18,20,22]$. Factors such as gender, presence of other systemic manifestations of $\mathrm{BD}$ and age at onset did not have any influence on prognosis $[14,42]$.

\section{Silent Neurological Involvement}

It has been described that patients with $\mathrm{BD}$ without overt neurological manifestation might have abnormal findings on neuropsychological, neurophysiological and neuroimaging studies, which represent silent neurological involvement $[20,35,43,44]$. Silent neurological involvement (SNI) is a milder neurological manifestation of NBD with reported rates between 20 and $40 \%$ [1,4,5]. The significance of this manifestation in unclear, however there are reports that patients with SNI may develop overt NBD with less severe clinical course [22].

Cognitive dysfunction occurs independently of neurological manifestation in $40-46 \%$ BD patients, with involvement of various cognitive domains such as visual and working memory, executive function, attention and language [44,45]. Risk factors for cognitive dysfunction are low educational level, anxiety, use of prednisone and systemic disease activity $[45,46]$, although association with disease exacerbations is unclear [43]. Patients may also present pseudobulbar affect and personality disorders [36].

\section{Progressive NBD}

NBD usually develop abruptly and generally clear completely within weeks. However a third of patients evolve with progressive course characterized by dementia, ataxia and dysarthria, with persistently elevated CSF IL-6 levels $[8,44]$. It usually occurs in the late stage of the disease when other neurological manifestations are stable and without clinical exacerbation of other BD symptoms [43]. Unfavorable clinical outcome in chronic progressive type is associated with brainstem atrophy $[8,40]$.

\section{Treatment}

There are no randomized trials on NBD treatment [49]. Acute presentations are managed with daily $1 \mathrm{~g}$ IV methylprednisolone infusions, followed by a slowly tapering course of oral steroids. At our center, patients with parenchymal NBD are usually managed with steroids and azathioprine or cyclophosphamide [11,42]. Other centers 
treat parenchymal NBD with steroids alone, using immunosuppressant agents in the presence of variables associated with poor prognosis, especially in relapsing cases, although there is not enough data to support that immunosuppressant agents prevent relapses [11,19,43]. Mycophenolate mofetil and methotrexate can be used in NBD treatment and cyclosporin should be used with caution due to neurotoxicity $[19,42]$.

Because non-parenchymal NBD have a more favorable prognosis, those manifestations are managed with steroids alone. CVTs are usually managed with anticoagulation and steroids in most centers $[19,42,43]$. Infliximabe is an option for refractory patients with continued benefit in follow-up studies over 4-year period [44,45,47-51]. Adalimumab and tocilizumab have been reported as an alternative to infliximab [52,53]. For progressive NBD, evidence from one center suggests that administering weekly methotrexate will help slow down the progressive neurological disease in association with a reduction in CSF interleukin-6 concentration [54].

\section{Conclusion}

NBD is a rare disease that presents variable neurological manifestations, including progressive form and silent neurological involvement. Patients that with parenchymal NBD present relapse more often when compared to non-parenchymal NBD. Biological agents are a treatment option for refractory cases.

\section{References}

1. Akman-Demir G, Bahar S, Coban O, Tasci B, Serdaroglu P (2003) Cranial MRI in Behçet's disease: 134 examinations of 98 patients. Neuroradiology 45: 851-859.

2. Neves FS, Caldas CA, Lage LV, Goldenstein-Schainberg C, Gonçalves CR (2009) Far away from the silk route: demographic and clinical features of Behçet's disease in 106 Brazilian patients. Clin Rheumatol 28: 543-546.

3. Sakane T, Takeno M, Suzuki N, Inaba G (1999) Behçet's disease. N Engl J Med 341: 1284-1291.

4. Kaklamani VG, Vaiopoulos G, Kaklamanis PG (1998) Behçet's Disease. Semin Arthritis Rheum 27: 197-217.

5. Mendoza-Pinto C, García-Carrasco M, Jiménez-Hernández M, Jiménez Hernández C, Riebeling-Navarro C, et al. (2010) Etiopathogenesis of Behcet's disease. Autoimmun Rev 9: 241-245.

6. No authors listed (1990) Criteria for diagnosis of Behçet's disease. International Study Group for Behçet's Disease. Lancet 335: 1078-1080.

7. Siva A, Saip S (2009) The spectrum of nervous system involvement in Behçet's syndrome and its differential diagnosis. J Neurol 256: 513-529.

8. Al-Araji A, Kidd DP (2009) Neuro-Behçet's disease: epidemiology, clinical characteristics, and management. Lancet Neurol 8: 192-204.

9. Qi J, Yang Y, Hou S, Qiao Y, Wang Q, et al. (2014) Increased Notch pathway activation in Behçet's disease. Rheumatology (Oxford) 53: 810-820.

10. Miller JJ, Venna N, Siva A (2014) Neuro-Behçet disease and autoinflammatory disorders. Semin Neurol 34: 437-443.

11. Gül A (2015) Pathogenesis of Behçet's disease: autoinflammatory features and beyond. Semin Immunopathol 37: 413-418.

12. Takeuchi M, Kastner DL, Remmers EF (2015) The immunogenetics of Behçet's disease: A comprehensive review. J Autoimmun 64: 137-148.

13. Yurdakul S, Yazici H (2008) Behçet's syndrome. Best Pract Res Clin Rheumatol 22: 793-809.

14. Dutra LA, Gonçalves CR, Braga-Neto P, Pedroso JL, Gabbai AA, et al. (2012) Atypical manifestations in Brazilian patients with neuro-Behçet's disease. J Neurol 259: 1159-1165.
15. Lannuzel A, Lamaury I, Charpentier D, Caparros-Lefebvre D (2002) Neurological manifestations of Behçet's disease in a Caribbean population: clinical and imaging findings. J Neurol 249: 410-418.

16. Ideguchi H, Suda A, Takeno M, Kirino Y, Ihata A, et al. (2010) Neurological manifestations of Behçet's disease in Japan: a study of 54 patients. J Neurol 257: 1012-1020.

17. Joseph FG, Scolding NJ (2007) Neuro-Behçet's disease in Caucasians: a study of 22 patients. Eur J Neurol 14: 174-180.

18. Kidd D, Steuer A, Denman AM, Rudge P (1999) Neurological complications in Behçet's syndrome. Brain 122 : 2183-2194.

19. Siva A (2001) Vasculitis of the nervous system. J Neurol 248: 451-468.

20. Akman-Demir G, Serdaroglu P, Tasçi B (1999) Clinical patterns of neurological involvement in Behçet's disease: evaluation of 200 patients. The Neuro-Behçet Study Group. Brain 122: 2171-2182.

21. SerdaroÄŸlu P (1998) Behçet's disease and the nervous system. J Neurol 245: 197-205.

22. Kalra S, Silman A, Akman-Demir G, Bohlega S, Borhani-Haghighi, et al. (2014) Diagnosis and management of Neuro-Behçet's disease: international consensus recommendations. J Neurol 261:1662-1676.

23. Dutra LA, Braga-Neto P, Pedroso JL, Guedes Bde V, de Souza LT, et al. (2011) Epilepsy and Behçet's disease: cortical and hippocampal involvement in Brazilian patients. J Neurol Sci 309: 1-4.

24. Noel N, Hutié M, Wechsler B, Vignes S, Le Thi Huong-Boutin D, et al. (2012) Pseudotumoural presentation of neuro-Behcet's disease: case series and review of literature. Rheumatology (Oxford) 51: 1216-1225.

25. Fountain EM, Dhurandhar A (2014) Neuro-Behçet's disease: an unusual cause of headache. J Gen Intern Med 29: 956-960.

26. Saip S, Siva A, Altintas A, Kiyat A, Seyahi E, et al. (2005) Headache in Behçet's syndrome. Headache 45: 911-919.

27. Mead S, Kidd D, Good C, Plant G (2000) Behçet's syndrome may present with partial seizures. J Neurol Neurosurg Psychiatry 68: 392-393.

28. Chroni E, Monastirli A, Polychronopoulos P, Pasmatzi E, Georgiou S, et al (2008) Epileptic seizures as the sole manifestation of neuro-Behçet's disease: complete control under interferon-alpha treatment. Seizure 17:744-747.

29. Aykutlu E, Baykan B, Serdaroglu P, Gökyigit A, Akman-Demir G (2002) Epileptic seizures in Behçet disease. Epilepsia 43: 832-835.

30. Coban O, Bahar S, Akman-Demir G, Tasci B, Yurdakul S, et al (1999) Masked assessment of MRI findings: is it possible to differentiate neuroBehçet's disease from other central nervous system diseases? Neuroradiology 41:255-260.

31. Yesilot N, Shehu M, Oktem-Tanor O, Serdaroglu P, Akman-Demir G (2006) Silent neurological involvement in Behçet's disease. Clin Exp Rheumatol 24: S65-70.

32. Graham D, McCarthy A, Kavanagh E, O’Rourke K, Lynch T (2013) Teaching NeuroImages: Longitudinally extensive transverse myelitis in neuro-Behçet disease. Neurology 80:189-191.

33. Uygunoglu U, Pasha M, Saip S, Siva A (2015) Recurrent longitudinal extensive transverse myelitis in a neuro-Behcet syndrome treated with infliximab. J Spinal Cord Med 38:111-114.

34. Yesilot N, Mutlu M, Gungor O, Baykal B, Serdaroglu P, et al. (2007) Clinical characteristics and course of spinal cord involvement in Behçet's disease. Eur J Neurol 14: 729-737.

35. Gökçay F, Celebisoy N, Kisabay A, Kumral E, Akyürekli O (2004) P300 and neuropsychological evaluation in Behçet's disease with and without neurological manifestations. J Neurol 251: 676-679.

36. Namer IJ, Karabudak R, Zileli T, Ruacan S, Küçükali T, et al. (1987) Peripheral nervous system involvement in Behçet's disease. Case report and review of the literature. Eur Neurol 26: 235-240.

37. Yoon BN, Kim SJ, Lim MJ, Han JY, Lee KW, et al. (2015) Neuro-Behçet's Disease Presenting as Hypertrophic Pachymeningitis. Exp Neurobiol 24: 252-255.

38. De Sousa DA, Mestre T, Ferro JM (2011) Cerebral venous thrombosis in Behçet's disease: A systematic review. J Neurol 258:719-727. 
Citation: Dutra LA, Barsottini OGP (2016) Neuro-Behçet's Disease: A Review of Neurological Manifestations and Its Treatment. J Vasc 2: 112.

Page 6 of 6

39. Seyahi E, Yurdakul S (2011) Behçet's Syndrome and Thrombosis. Mediterr J Hematol Infect Dis 3: e2011026.

40. Cantarini L, Vitale A, Bersani G, Nieves LM, Cattalini M, Lopalco G, et al. (2016) PFAPA syndrome and Behçet's disease: a comparison of two medical entities based on the clinical interviews performed by three different specialists. Clin Rheumatol 35:501-505.

41. Noel N, Bernard R, Wechsler B, Resche-Rigon M, Depaz R, et al. (2014) Long-term outcome of neuro-Behçet's disease. Arthritis Rheumatol 66 1306-1314.

42. Siva A, Kantarci OH, Saip S, Altintas A, Hamuryudan V, et al. (2001) Behçet's disease: diagnostic and prognostic aspects of neurological involvement. J Neurol 248: 95-103.

43. Oktem-Tanar O, Baykan-Kurt B, , Akman-Demir G, SerdaroÄŸlu P (1999) Neuropsychological follow-up of 12 patients with neuro-Behçet disease. J Neurol 246: 113-119.

44. Cavaco S, da Silva AM, Pinto P, Coutinho E, Santos E, et al. (2009) Cognitive functioning in Behçet's disease. Ann N Y Acad Sci 1173 217-226.

45. Monastero R, Camarda C, Pipia C, Lopez G, Camarda LK, et al. (2004) Cognitive impairment in Behçet's disease patients without overt neurological involvement. J Neurol Sci 220: 99-104.

46. Dutra LA, de Souza AW, Alessi H, Guedes Bde V, Braga-Neto P, et al (2013) Cognitive impairment in Brazilian patients with Behçet's disease occurs independently of neurologic manifestation. J Neurol Sci 327: 1-5.
47. Kikuchi H, Aramaki K, Hirohata S (2008) Effect of infliximab in progressive neuro-Behçet's syndrome. J Neurol Sci 272: 99-105.

48. Oliveira AC, Buosi AL, Dutra LA, de Souza AW (2011) Behçet disease: clinical features and management in a Brazilian tertiary hospital. J Clin Rheumatol 17: 416-420.

49. Yoon DL, Kim YJ, Koo BS, Kim YG, Lee CK, et al. (2014) Neuro-behçet's disease in South Korea: clinical characteristics and treatment response. Int J Rheum Dis 17: 453-458.

50. Pipitone N, Olivieri I, Padula A, D'angelo S, Nigro A, et al. (2008) Infliximab for the treatment of Neuro-Behçet's disease: a case series and review of the literature. Arthritis Rheum 59: 285-290.

51. Fasano A, D'Agostino M, Caldarola G, Feliciani C, De Simone C (2011) Infliximab monotherapy in neuro-Behçet's disease: four year follow-up in a long-standing case resistant to conventional therapies. J Neuroimmunol 239: 105-107.

52. Leccese P, D'Angelo S, Angela P, Coniglio G, Olivieri I (2010) Switching to adalimumab is effective in a case of neuro-Behcet's disease refractory to infliximab. Clin Exp Rheumatol 28: S102.

53. Shapiro LS, Farrell J, Borhani Haghighi A (2012) Tocilizumab treatment for neuro-Behcet's disease, the first report. Clin Neurol Neurosurg 114: 297-298.

54. Hirohata S, Suda H, Hashimoto T (1998) Low-dose weekly methotrexate for progressive neuropsychiatric manifestations in Behcet's disease. J Neurol Sci 159: 181-185 